\title{
Inclusion of Three-Vessel View in Routine Fetal Cardiac Screening
}

\author{
Subedi K, Chataut D, Khanal UP, Ansari MA, Pradhan S \\ Department of Radiology, Tribhuvan University Teaching Hospital, Kathmandu, Nepal
}

\begin{abstract}
Aims: The purpose of this study was to study the feasibility of inclusion of 3-vessel view (3-VV) of the fetal upper mediastinum in routine fetal anomaly screening; and to study the size relationship of these vessels namely, main pulmonary artery (MPA), ascending aorta (AA) and the superior venacava (SVC) in fetuses between 17 and 24 weeks of pregnancy by antenatal ultrasound.
\end{abstract}

Methods: This was a prospective cross sectional study involving 106 pregnant ladies between 17 and 24 weeks of gestation. The time burden to the examination due to addition of $3-\mathrm{VV}$ in routine anomaly screening was recorded. The relationships of the three great vessels of the fetal upper mediastinum were studied and their diameters were obtained. Regression equations were used to construct the reference ranges for all the parameters of statistical significance.

Results: The 3-VV could be easily obtained in all but eight patients within five minutes (the difficulty in these eight patients was due to fetal position). The MPA, AA and SVC were aligned in a straight line from left to right respectively, the MPA being the largest vessel, the SVC being the smallest vessel and the AA having an intermediate diameter. All of these three vessels showed significant correlation of size with advancing gestational age.

Conclusions: $3-\mathrm{VV}$ is easily obtained in fetuses at the time of routine anomaly screening. This should be routinely included in the screening ultrasound of fetal heart along with the four-chamber view to detect the anomalies of the outflow tract.

Keywords: 3-vessel view, antenatal ultrasound, ascending aorta, main pulmonary artery, superior venacava.

\section{INTRODUCTION}

Congenital heart disease is the most common form of severe congenital abnormality with an incidence of 4-8/1000 live births. ${ }^{-4}$ The four-chamber view, the examination used in routine cardiac screening, detects only upto $60 \%$ of the cardiac anomalies ${ }^{5-7}$ missing the anomalies involving the great vessels and outflow tracts. ${ }^{4,8-16}$ These anomalies could be detected by detailed longitudinal views ${ }^{8,11,17-19}$ but, such an examination is time consuming and requires expertise. $^{8-10,14,20,21}$

The 3-vessel view (3-VV), introduced by Yoo et $\mathrm{al}^{22,23}$ is an axial view of the fetal upper mediastinum where the main pulmonary artery, ascending aorta

\section{CORRESPONDENCE}

Dr Kamal Subedi

Department of Radiology, Tribhuvan University Teaching

Hospital, Kathmandu, Nepal

Email: ksubedi80@gmail.com

Phone: +977-9841781213 and superior venacava are aligned in a straight line from the left to right. The primary advantage of this methodology is the shorter time required to visualize the great vessels and outflow tracts compared to the traditional long-axis view. ${ }^{22,23}$

In Nepalese context as well, the problems with evaluation of outflow tracts could be overcome by including $3-\mathrm{VV}$ in routine cardiac screening. So this study is being undertaken to study the feasibility of inclusion of the $3-\mathrm{VV}$ in routine antenatal anomaly screening. The spatial arrangement and diameters of the vessels will also be studied.

\section{METHODS}

This was a prospective cross sectional study involving uncomplicated 106 singleton pregnancies between 17 and 24 weeks of gestation referred for routine obstetric ultrasonographic examination Medical ethics committee, Institute of Medicine, approved the study protocol and all the participants 
gave prior informed consent. Study was conducted in the Department of Radiology, Tribhuvan University Teaching Hospital from September 2008 to August 2009.

Singleton pregnancies with period of gestation between 17 to 24 weeks determined by reliable last menstrual period or ultrasound examination before 20 weeks of gestation without any complication in the current pregnancy or known risk factors of adverse pregnancy outcome were included in the study. Pregnancies with undetermined period of gestation, maternal smoking, multiple pregnancies, diagnosed fetal abnormality in current pregnancy, pre-existing medical condition (such as hypertension, diabetes mellitus, renal disease) and women not willing to give consent for the examination were excluded from the study.

The study was carried out with a $3.5 \mathrm{MHz}$ curvilinear probe in Toshiba Nemio ultrasound machine (Toshiba Corporation, Japan) by single examiner. All patients were examined in supine position. The three-vessel view was acquired by sliding the transducer cephalad from the four-chamber plane, which showed round cross-sections of the AA and SVC and an oblique section of the MPA. In this plane, the MPA, AA, and SVC are arranged in a straight line from the left anterior mediastinum to the right posterior mediastinum. Once a satisfactory three-vessel view was acquired, the image was magnified, and then the sizes of the great vessels were measured by placing the electronic calipers from the inner-to- the inner wall. The visibility of the $3-\mathrm{VV}$ and the mean time added to the examination due to addition of this parameter in the routine anomaly scan, the diameters of the three vessels and the relationship of these vessels in the mediastinum were recorded.

Data obtained were compiled and analyzed using standard statistical analysis. SPSS 16.0 was utilized for the data analysis. Feasibility of visualization of $3-\mathrm{VV}$ and mean time required for the same were recorded. Pierson correlation was used to see the relation of diameter of the three vessels with advancing gestational age. Reference values for the diameter of the three vessels were obtained for the gestational ages between 17 and 24 weeks. Linear regression was performed and regression equations were obtained for the different parameters.

\section{RESULTS}

The three vessels (main pulmonary artery, ascending aorta and superior venacava) were studied in 106 singleton pregnancies meeting the inclusion criteria.

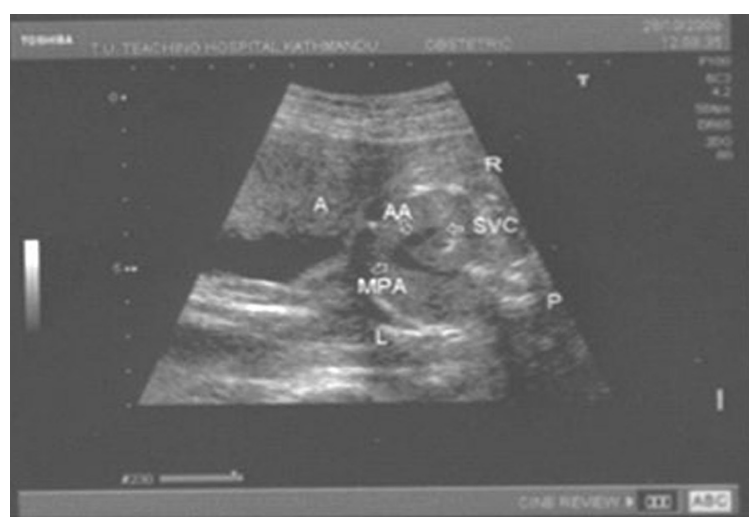

Figure 1. Three- vessel view of the fetal heart. A-anterior, P-posterior, R-right, L-left, MPAMain pulmonary artery, AA-Ascending aorta, SVC- Superior venacava.

Maximum numbers of pregnancies were between 20 - 24 weeks (14.15\% each) and minimum numbers (9.43\% each) were in 17 and 19 weeks. $8.49 \%$ were primi gravida whereas $41.51 \%$ were multi gravida. Maternal age ranged from 18 to 32 years (mean-24 years). Highest numbers of patients were in the age of 22 years.

\section{Feasibility of the visualization of 3-VV}

Of the total 106 pregnancies, the ultrasound study had to be repeated in 8 patients after an interval of half to one hour due to difficulties of the visualization in prone and prone oblique fetal position, the vessels being obscured by the fetal spine in such cases. In all other cases, the $3-\mathrm{VV}$ was obtained in less than five minutes.

\section{Correlation with period of gestation}

All of the three vessels showed a significant positive correlation of size with advancing gestational age (Table1). The main pulmonary artery showed the highest correlation $(\mathrm{r}=0.882)$ with advancing gestational age. 
Table 1. Correlation of diameter of three vessels with gestational age $(n=106)$.

\begin{tabular}{lll}
\hline $\begin{array}{l}\text { Parameters (in } \\
\text { millimeters) }\end{array}$ & $\begin{array}{l}\text { Pierson } \\
\text { Correlation }(r) \\
\text { with period of } \\
\text { gestation }\end{array}$ & p value \\
\hline $\begin{array}{l}\text { Main pulmonary } \\
\text { artery }\end{array}$ & 0.882 & 0.001 \\
Ascending aorta & 0.843 & 0.001 \\
Superior venacava & 0.725 & 0.001 \\
\hline
\end{tabular}

Reference values

Gestational age specific mean values with standard deviations and the percentile values (5th, 50th and 95th) were calculated for all of the three vessels (Tables 2, 3 and 4).

The main pulmonary artery was the largest vessel with a diameter of $2.54 \pm 0.35 \mathrm{~mm}$ at 17 weeks of gestation, increasing to $5.56 \pm 0.60 \mathrm{~mm}$ at 24 weeks. The superior venacava was the smallest vessel with a diameter of $1.36 \pm 0.25 \mathrm{~mm}$ at 17 weeks, increasing to $2.76 \pm 0.49 \mathrm{~mm}$ at 24 weeks. The ascending aorta had an intermediate size between these vessels.

Table 2. Mean, standard deviations and the percentiles $\left(5^{\text {th }}, \mathbf{5 0}^{\text {th }}\right.$ and $\left.\mathbf{9 5}^{\text {th }}\right)$ for diameter main pulmonary artery $(n=106)$.

\begin{tabular}{|c|c|c|c|c|}
\hline $\begin{array}{l}\text { G.A. } \\
\text { (weeks) }\end{array}$ & $\begin{array}{l}\text { Mean } \pm S D \text { in } \\
\mathrm{mm}\end{array}$ & 5 & $\begin{array}{l}\text { Percentile } \\
50 \\
\text { (median) }\end{array}$ & 95 \\
\hline 17 & $2.54 \pm 0.35$ & 2.00 & 2.55 & 3.10 \\
\hline 18 & $3.10 \pm 0.31$ & 2.60 & 3.10 & 3.80 \\
\hline 19 & $3.43 \pm 0.47$ & 2.90 & 3.30 & 4.30 \\
\hline 20 & $3.92 \pm 0.38$ & 3.40 & 3.90 & 4.80 \\
\hline 21 & $4.32 \pm 0.62$ & 3.40 & 4.30 & 5.40 \\
\hline 22 & $4.62 \pm 0.54$ & 3.90 & 4.60 & 5.80 \\
\hline 23 & $5.06 \pm 0.55$ & 4.30 & 5.0 & 6.30 \\
\hline 24 & $5.56 \pm 0.60$ & 4.70 & 5.60 & 6.90 \\
\hline
\end{tabular}

Table 3. Mean, standard deviation and the percentiles $\left(5^{\text {th }}, \mathbf{5 0}^{\text {th }}\right.$ and $\left.95^{\text {th }}\right)$ for diameter of ascending $\operatorname{aorta}(n=106)$.

\begin{tabular}{lllcl}
\hline $\begin{array}{l}\text { G.A. } \\
\text { (weeks) }\end{array}$ & $\begin{array}{l}\text { Mean } \pm \text { SD } \\
\text { in } \mathrm{mm}\end{array}$ & 5 & $\begin{array}{c}\text { Percentile } \\
50 \\
\text { (median) }\end{array}$ & 95 \\
\hline 17 & $2.27 \pm 0.31$ & 1.70 & 2.30 & 2.80 \\
18 & $2.76 \pm 0.29$ & 2.30 & 2.70 & 3.40 \\
19 & $3.00 \pm 0.38$ & 2.50 & 2.90 & 3.70 \\
20 & $3.30 \pm 0.34$ & 2.80 & 3.30 & 4.10 \\
21 & $3.62 \pm 0.49$ & 3.00 & 3.60 & 4.80 \\
22 & $3.84 \pm 0.46$ & 3.20 & 3.80 & 4.80 \\
23 & $4.10 \pm 0.47$ & 3.40 & 4.10 & 5.10 \\
24 & $4.46 \pm 0.49$ & 3.70 & 4.50 & 5.50 \\
\hline
\end{tabular}

Table 4. Mean, standard deviation and the percentiles $\left(5^{\text {th }}, \mathbf{5 0}^{\text {th }}\right.$ and $\left.\mathbf{9 5}^{\text {th }}\right)$ for diameter of superior venacava $(n=106)$.

\begin{tabular}{llccc}
\hline $\begin{array}{l}\text { G.A. } \\
\text { (weeks) }\end{array}$ & $\begin{array}{l}\text { Mean } \pm \text { SD in } \\
\mathrm{mm}\end{array}$ & 5 & $\begin{array}{l}\text { Percentile } \\
50 \\
\text { (median) }\end{array}$ & 95 \\
\hline 17 & $1.36 \pm 0.25$ & 1.00 & 1.30 & 1.90 \\
18 & $1.66 \pm 0.30$ & 1.00 & 1.70 & 2.30 \\
19 & $1.82 \pm 0.41$ & 1.10 & 1.80 & 2.50 \\
20 & $2.02 \pm 0.43$ & 1.20 & 2.10 & 2.80 \\
21 & $2.20 \pm 0.43$ & 1.30 & 2.30 & 3.00 \\
22 & $2.38 \pm 0.42$ & 1.40 & 2.30 & 3.30 \\
23 & $2.54 \pm 0.42$ & 1.50 & 2.50 & 3.50 \\
24 & $2.76 \pm 0.49$ & 1.60 & 2.80 & 3.80 \\
\hline
\end{tabular}

Regression equations

Linear regression was performed for the different parameters using the gestational age as the independent variable and regression equations were obtained (Table 5).

Table 5. Linear regression for different parameters using gestational age as independent variable.

\begin{tabular}{lllllllll}
\hline Constant & B & SE & t & P & \multicolumn{2}{c}{$95 \% \mathrm{Cl}$} & $\mathrm{R}^{2}$ \\
& & & value & value & $\begin{array}{l}\text { Lower } \\
\text { bound }\end{array}$ & $\begin{array}{l}\text { Upper } \\
\text { bound }\end{array}$ & \\
& & & & & & & & \\
\hline MPA & -4.434 & 0.415 & 0.022 & 19.101 & 0.001 & 0.372 & 0.458 & 0.776 \\
AA & -2.604 & 0.294 & 0.018 & 16.000 & 0.001 & 0.258 & 0.330 & 0.708 \\
SVC & -1.794 & 0.190 & 0.018 & 10.732 & 0.001 & 0.155 & 0.225 & 0.521 \\
\hline
\end{tabular}




\section{DISCUSSION}

The three vessel view introduced by Yoo et $\mathrm{al}^{22}$ and subsequently adapted by other authors provides for the shortcomings of the four chamber view and the long axis view of the outflow tracts. The easy anatomy and the short time required for the acquisition further add to the benefits of the $3-\mathrm{VV}$ in the antenatal cardiac screening.

We prospectively evaluated uncomplicated 106 singleton pregnancies in the second trimester between 17 and 24 weeks. The 3-VV was easily acquirable and did not need expertise in fetal echocardiography. We could easily obtain this view in our patients within a short span of time without significant increase in time burden.

The mean diameters of the three vessels, standard deviations and $95^{\text {th }}$ confidence intervals were calculated. All of these parameters showed significant correlation $(\mathrm{p}<0.005)$ with the advancing gestational age (Table 1). All observations confirm the previous studies.

After the introduction of 3-VV by Yoo et al, Yagel et $\mathrm{al}^{24}$ described the 3-vessel and trachea view (3-VT) in pregnancies between 13 and 23 weeks and established a reference range for six parameters from this view: the pulmonary artery, proximal aortic arch, distal aortic arch, the superior venacava, ductus arteriosus and trachea. Mean and 95\% CI of the MPA diameter in their study was $1.75(1.61-1.89) \mathrm{mm}$ at 17 weeks, which increased to $2.91(2.63-3.18) \mathrm{mm}$ at 23 weeks. These values are smaller compared to our study where the mean values for these ages are $2.54(2.0-3.1) \mathrm{mm}$ and $5.0(4.3-6.3) \mathrm{mm}$ respectively (Table 2 ). The aorta was divided into the proximal and distal arch by these authors. The proximal arch corresponded with the ascending aorta in our study. The diameters of the proximal arch were $1.19(1.09-1.29) \mathrm{mm}$ and 2.17 (1.96-2.38) $\mathrm{mm}$ at 17 and 23 weeks respectively with a gradual increasing trend. These parameters are also smaller compared to our study in which the ascending aortic diameter was 2.27 (1.7-2.3) $\mathrm{mm}$ and 4.10 (3.4$5.1) \mathrm{mm}$ at 17 and 23 weeks of gestation respectively (Table 3). However, the mean diameters of superior venacava were larger in their study as compared to our study; 1.95 (1.85-2.06) $\mathrm{mm}$ and 2.82 (2.58-3.05) $\mathrm{mm}$ against $1.36(1.0-1.9) \mathrm{mm}$ and 2.54 (1.50-3.50) $\mathrm{mm}$ at 17 and 23 weeks of gestation respectively
(Table 4). These authors have also produced ratios with pulmonary artery and the ductus arteriosus as the numerators which is not applicable in our study.

Zalel et $\mathrm{al}^{25}$ studied the MPA, aorta and SVC in 338 fetuses between 14 and 38 weeks of gestation. These authors also verified the size relationship of these vessels, MPA being the largest and SVC being the smallest. The correlation coefficient between gestational age and the diameter of the vessels were $r=0.93, r=0.93$ and $r=0.86$ for pulmonary artery, aorta and SVC respectively (all found to be highly statistically significant $(\mathrm{p}<0.001)$. These findings are in accordance with our study where the correlation coefficients were $r=0.882, r=0.843$ and $r=0.725$ for MPA, AA and SVC respectively (Table 1). Mean and 95\% CI of the MPA diameter in their study was 2.28 (0.29 - 2.19) $\mathrm{mm}$ at $16-17$ weeks, which increased to $4.60(0.67-4.41) \mathrm{mm}$ at $24-25$ weeks. As compared to the study of Yagel et $\mathrm{al}^{24}$, these values are larger but are smaller compared to our study. The mean values with advancing gestational age in this study are not statistically significant from our study ( $p>0.05)$.

Moon et a ${ }^{26}$ measured the three vessels prospectively in 1538 fetuses between 14 and 38 weeks of gestation. The size of each vessel had a significant positive relationship with GA ( $p<0.001)$. They have emphasized in the evaluation of the size discrepancy of the vessels and produced the ratios of the size relationship of these vessels as well. Yagel et $\mathrm{al}^{24}$ believe that the wide variance in measurements among fetuses is attributable to anatomical variation, not to low reproducibility in the measurements themselves.

The significance of the reference values lies in establishing the normal values of the vessels during routine fetal scan, if the size relationship is abnormal. These reference values might help in such instances in our context.

\section{CONCLUSIONS}

The 3-VV is easily obtainable and along with the fourchamber view, it should be included in the routine fetal cardiac screening to detect the abnormalities of outflow tracts. The reference ranges of the vessels in this study will be valuable for establishing the normality of the vessels during fetal cardiac screening. However, for corroboration of our findings, a larger study involving larger sample size and a 
wider gestational age range with multiple ultrasound examinations during the same pregnancy is required.

\section{DISCLOSURE}

The authors report no conflicts of interest in this work.

No violation of human rights and safety.

Funding: Nil

\section{REFERENCES}

1. Hoffman JI, Christianson R. Congenital heart disease in a cohort of 19,502 births with long-term follow-up. Am J Cardiol. 1978;42(4):641-7.

2. Young ID, Clarke M. Lethal malformations and perinatal mortality: a 10 year review with comparison of ethnic differences. BMJ. 1987;295(6590):89-91.

3. Hoffman JI, Kaplan S. The incidence of congenital heart disease. J Am Coll Cardiol. 2002;39(12):1890-900.

4. Gembruch U. Prenatal diagnosis of congenital heart disease. Prenat Diagn. 1997;17(13):1283-98.

5. Mahle WT, Clancy RR, McGaurn SP, Goin JE, Clark BJ. Impact of prenatal diagnosis on survival and early neurologic morbidity in neonates with the hypoplastic left heart syndrome. Pediatrics. 2001;107(6):1277-82.

6. Allan LD, Crawford DC, Chita SK, Tynan MJ. Prenatal screening for congenital heart disease. BMJ. 1986;292:17179.

7. Cople JA, Pilu G, Green J, Hobbins JC, Kleinman CS. Fetal echocardiographic screening for congenital heart disease: the importance of the four-chamber view. Am J Obstet Gynecol. 1987;157:648-55.

8. Achiron R, Glaser J, Gelernter I, Hegesh J, Yagel S. Extended fetal echocardiographic examination for detecting cardiac malformations in low risk pregnancies. BMJ. 1992;304:343-6.

9. Stumpflen I, Stumpflen A, Wimmer M, Bernaschek G. Effect of detailed fetal echocardiography as part of routine prenatal ultrasonographic screening on detection of congenital heart disease. Lancet. 1996;348(9031):854-7.

10. Ott WJ. The accuracy of antenatal fetal echocardiography screening in high- and low-risk patients. Am J Obstet Gynecol. 1995;172(6):1741-7.

11. Bromley B, Estroff JA, Sanders SP, Parad R, Roberts D, Frigoletto FD Jr, et al. Fetal echocardiography: accuracy and limitations in a population at high and low risk for heart defects. Am J Obstet Gynecol. 1992;166:1473-81.

12. Benacerraf BR. Sonographic detection of fetal anomalies of the aortic and pulmonary arteries: value of four-chamber view vs direct images. AJR. 1994;163(6):1483-9.

13. Sharland GK, Allan LD. Screening for congenital heart disease prenatally. Results of a $21 / 2$-year study in the South East Thames Region. Br J Obstet Gynaecol. 1992;99:220-5.

14. Wigton TR, Sabbagha RE, Tamura RK, Cohen L, Minogue JP, Strasburger JF. Sonographic diagnosis of congenital heart disease: comparison between the four-chamber view and multiple cardiac views. Obstet Gynecol. 1993;82:219. 24.

15. Wyllie J, Wren C, Hunter S. Screening for fetal cardiac malformations. Br Heart J. 1992;71 (Suppl. 4):20-7.
16. Yagel S, Weissman A, Rotstein Z, Manor M, Hegesh J, Anteby E, et al. Congenital heart defects: natural course and in utero development. Circulation. 1997;96(2):550-5.

17. Benacerraf BR, Pober BR, Sanders SP. Accuracy of fetal echocardiography. Radiology. 1987;165:847-9.

18. DeVore GR. The aortic and pulmonary outflow tract screening examination in the human fetus. J Ultrasound Med. 1992;11:345-8.

19. Kirk JS, Riggs TW, Comstock CH, Lee W, Yang SS Weinhouse E. Prenatal screening for cardiac anomalies: the value of routine addition of the aortic root to the fourchamber view. Obstet Gynecol. 1994;84:427-31.

20. Yagel S, Cohen SM, Achiron R. Examination of the fetal heart by five short-axis views: a proposed screening method for comprehensive cardiac evaluation. Ultrasound Obstet Gynecol. 2001;17(5):367-9.

21. Rustico MA, Benettoni A, D’Ottavio G, Maieron A, FischerTamaro I, Conoscenti G, et al. Fetal heart screening in lowrisk pregnancies. Ultrasound Obstet Gynecol. 1995;6:3139.

22. Yoo SJ, Lee YH, Kim ES, Ryu HM, Kim MY, Choi HK, et al. Three-vessel view of the fetal upper mediastinum: an easy means of detecting abnormalities of the ventricular outflow tracts and great arteries during obstetric screening. Ultrasound Obstet Gynecol. 1997;9:173-82.

23. Yoo SJ, Lee YH, Cho KS. Abnormal three-vessel view on sonography: a clue to the diagnosis of congenital heart disease in the fetus. AJR. 1999;172(3):825-30.

24. Yagel S, Arbel R, Anteby EY, Raveh D, Achiron R. The three vessels and trachea view (3VT) in fetal cardiac scanning. Ultrasound Obstet Gynecol. 2002;20(4):340-5.

25. Zalel Y, Wiener Y, Gamzu R, Herman A, Schiff E, Achiron R. The three-vessel and tracheal view of the fetal heart: an in utero sonographic evaluation. Prenat Diagn. 2004;24:1748.

26. Moon MH, Cho JY, Park EJ, Min JY, Kim JA, Jung S, et al. Three-vessel view of the fetal heart: in utero development of the great vessels. Prenat Diagn. 2007;27:158-63. 